\title{
The Controls of Exit on The Origin of The Linguistic Structures- Nominal Sentence as A Model
}

\author{
Ali Salama Abu Sharif, Professor of Grammar at Education College, Prince Sattam bin Abdulaziz University \\ Al-Kharj, Saudi Arabia. \\ Maliha Mohammed Al-Qahtani, Associate Professor of Grammar and Language at Education College, \\ Prince Sattam bin Abdulaziz University, Al-Kharj, Saudi Arabia.
}

\begin{abstract}
The Arabs have built their linguistic structures upon explicit and eminent origins. It is not permissible to omit or to separate between the collateral except with evidence. It is not acceptable to transmit the arrangement between the two pillars of the chain. Moreover, it is not allowed to progress or delay without evidence. However, the richness of the language, its flexibility, and the expansion of its structures permitted us to deviate from these principles with a set of justifications and controls that the research deals with in its content. Therefore, the research has dealt with deletion and the phenomenon of progress and delay between the two parts of the transmission chain. It is revealed that the study of the declarative structure has played an influential role in realizing the sentence meanings and speech purposes. It is concluded that omission and progress, and delay of linguistic structures are subjected to control without compromising the meaning's validity and relevance to the context. Moreover, it is emphasized to study the phenomenon of deviating from the origin of linguistic, religious, and literary heritage.
\end{abstract}

Keywords: Linguistic Structures, Nominal Sentence, explicit and eminent origins Received: 09.12.2020 $\quad$ Accepted: 21.01.2021 $\quad$ Published: 05.02.2021

\section{INTRODUCTION}

The one who summarizes and communicates about Arabic grammar expresses a tremendous impact on the Arab mind effects. It is because of its accuracy in observation and its activity in collecting what has been separated. Its contemplation carries its appreciation. The Arabs have the right to be proud of it (Mahdi, 1990). The grammarians have put the rules and principles for linguistic structures. It is not permissible to deviate from these without a justification. This justification may be from the use of the Arabs or the requirements of the grammatical industry. The research has collected these justifications in the nominal structure after exploring it from the essential grammar sources in the Arab library. The sentence in the ancient and contemporary linguistic code is launched to the complex speech of two words attributed to the other (Al-Zamakhshari, 1993). For example, wholesome is entirely beneficial (Al-Akbari, 1992).

Here the contemporary researcher has combined these two constraints (composition and statement). He has defined speech or sentence as the composition of two or more words with an independent expressive meaning (Hassan, 2020). The declarative structures in the Arabic language have restrictions. These cannot be broken except with justifications. The essential controls include mentioning the two parts of the structure. It is not possible to delete these together or to delete one of these without a justification. It is necessary to arrange the two parts of the composition according to the rules of the language. It is not possible to mention which is delayed except with a justification or delay what is entitled to progress without justification. The Arabic linguists have perceived the linguistic heritage in the extrapolation of their texts. They have found the action of linguistic elements in each other. They have established the declarative structures based on a factor, an action, and a syntactic movement. This is because the singular words are not designed to know their meanings in themselves. Preferably, these must be joined together to avail the combined benefits. There must be a coalition and harmony between the words to establish the meanings in the addressee's mind.

The copyists that have abrogated the rule of initiation in the nominative sentence have included three chapters. Before this linguistic structure, the question arises regarding copying the rule of initiation and removing its meaning and action. It is an independent structure, or more precisely, justification is required for these tools in transcribing the rule of initiation in the nominal structure. These have transcribed their resemblance to transitive verbs. These have developed the confusion of the subject to which these are ascribed as an attribute. The attribute is restricted to the meaning of the verb that is 
attributed to proving, denying, becoming, restricting a specific time, and so on. It is not permissible to separate the factor and factorization in the linguistic norms such as the separation between the source and his object, the connection and its conductor, and the verb. However, the separation between the factor and the object may be tolerated in a semi-sentence (adverb, preposition). It is permissible in such a situation to separate the name from the predicate according to its action.

The research problem is represented in the phenomenon of deviating from the original in linguistic structures. It is one of the phenomena of the Arab heritage that is monitored by the grammatical sources. There are many such concerns, and these are complex. There is much disagreement about it. It needs to be collected, classified, and reformulated. The research has focused on seeking out linguistic phenomena that have deviated from their linguistic, structural system origins. It has attempted to find the controls that have governed the linguistic structure from the origin concerning the nominal sentence. It explores the impact of the phenomenon of deviation from the original on the composition and context. In dealing with this phenomenon, the research has relied on the descriptive and analytical method. It is represented in reading the syntactic heritage, a systematic reading to determine the exponential origins of linguistic compositions. It formulates the regulations for departing from the origin in linguistic structures through linguistic use. The research has dealt with its content with two basic phenomena. These are related to the nominal structure. These are the deletion phenomenon, the phenomenon of progress, and the delay between the two parts of the transmission chain.

The research has focused on the permissible exit and not the obligatory exit in dealing with these two phenomena. It is because of the obligatory deletion, or the obligatory progress possessed required in the grammatical industry. The research has aimed to explore the phenomenon that has departed from the established principles of linguistic compositions. It would help determine the reasons that have facilitated the discourse's production to depart from the structure's origin. It enriches the Arab library with specialized research that monitors language phenomena and addresses these to demonstrate the flexibility, breadth, and comprehension of all that occurs to the origins of their structures change. To achieve the purpose, the research is comprised of two sections. In the first section, the research deals with the phenomenon of deletion in linguistic compositions. In the second section, the research deals with the phenomenon of progress and delay. This section enlightens the rationale for progressing, which is entitled to delay or delay and is entitled to progress between the two components of the sentence's composition.

\section{Deletion in Linguistic Structures}

One of the exponential phenomena in the Arabic language is the phenomenon of deletion. It is adopted due to the briefness of language and the presence of current evidence. It depends upon the listener's perception, the speaker's rhetoric, the origin in the Arabs' speech, and lack of ambiguity. Therefore, it is not permissible to delete one of the two pillars of the chain of transmission without evidence. It is essential for completion, and deletion is temporal (Al-Tamimi, 1995). It is taken from the use of the Arabs' linguistic structures. Every letter is not appearing after the verb, in which the verb is deleted. It is atrophied after the letters and positions that the Arabs have harmed by showing (Brinker, 2010). However, deletion in linguistic structures is subjected to restrictions. The first restriction is the presence of a trace indicating the omission. It is estimated whether it is a syntactic movement, a meaning is required by the composition, or a factor is requiring an action.

Because the meaning is understood without the wording for evidence, it is permissible not to bring it. It is intended as a judgment and appreciation. The Arabs' customs in their speech are abbreviated when understanding the meaning, and the word is intended to indicate the meaning. This rule is framed in declarative structures, such as deleting the subject or predicate, deleting a verb, subject, object, and deleting operators if it is evidenced by deleting tools. The second restriction is regarded as evidence of omission. One of the Arabs' customs is that nothing is omitted as a necessity or permissibility except with a presumption that defines it in their speech. So, the Arabs have omitted the sentence, the word, the letter, and the diacritical mark, all with evidence (Al-Khatib, 2006).

The evidence is considered as an indication of omission from the article or the linguistic context. Almighty God says, "End well for you" (Qur'an 4:171). Good is erected by omission, which can be known from the context. It has happened that when we see a man giving people, we say: (Zaid), the meaning is: (Give Zaid), deleting the accusative verb is the sign of the place on him. The third restriction has implemented that the appearance must not prejudice the meaning. The basic principle in linguistic compositions is preserving the validity of the meaning. From this point of view, one of the deletion controls in the Arabic language estimates has followed the meaning and appropriate to the context.

Deleting the subject in the nominal composition is depended on interest. The predicate is the subject of interest, and the speech is called a useful sentence in the presence of both. So, these are necessary until 
the desired benefit from this composition is obtained, and it is evidenced in the mind of the addressee. Nevertheless, the language has represented in the subject that it may be deleted in some situations. It can be deleted if you find a current circumstance that identifies the omission. Sibawayh (1988) has represented to him by saying: "And you saw a picture of a person, so it became a sign for you to know the person, so you said: (Abdullah), as if you said: (That is Abdullah), or: (This is Abdullah)."

Furthermore, it can be deleted if you find a verbal presumption that you feel necessary (Hammouda, 2020). Here is an interrogative statement that needs an answer: (When to travel?) and Answer: (Tomorrow). He has omitted the subject of the question mark. Similarly, while answering the condition (if, then), which is called (if, then) penalty, this position is adopted steadily and abundant in the Arabic language. Moreover, after pronouncing the saying and what is derived from nouns or verbs, the subject is frequently omitted depending on the verbal context that defines it. It is a common and steady approach in the Arabic language. For example: "And Khawlan said, then marry the girl" (Al-Andalusi, 2010). Here, Khawlan has justified the omission and made the right words to say. It has appealed to a concise speech in which the subject is mentioned. Therefore, the language has justified the omission of the subject based on the previous verbal presumption.

Moreover, in one narration, the Almighty God's saying has been translated: "And they said the Most Merciful took a son, praising Him, but worshipers are honorable" (Qur'an 21:26). Al-Nahas (2000) has translated it: "They are honorable servants." If the subject is transcribed with (was) or one of its sisters, it is not permissible to delete it (Al-Andalusi, 2010). It is not permissible to abrogate in the nominative sentence by one of the verbs (almost) and its sisters, hope verbs (hopefully) and its sisters, or verbs of creation (make) and its sisters. The perpetrator is not permissible to dispose of by deletion, neither by abbreviation nor by limitation, and the act of omitting the subject that is her name because it is in the place of the subject. If the nominative sentence is copied with a letter from the letters of the topic (that) and its sisters, it is permissible to delete the name if its meaning is understood.

Linguists have stipulated that the deletion is not specific to poetry. However, it has occurred more in poetry than in others. They have narrated it: "Your Zaid is taken" (Sibawayh, 1988; Al-Nahas, 2000). It is also mentioned in the hadith of the Prophet (PBUH): "Indeed, among the most severe people are the victims of the resurrection day" (Sunan al-Nasa'i, 8:216). If it enters the nominal composition (no) that denies gender, then deleting the subject is limited to hearing. Sibawayh (1988) has talked about Arabs: "You do not have to." It is also said: "Rather he wants: It is okay for you, and you do not have anything, but it is omitted for their frequent use of it" (Shebel, 2009). Moreover, (no) denies gender in its entry into the nominative sentence. It has given off the denial of (who) from it in the question. So, it is not permissible to delete the denial and keep (who). It is not permissible to delete the denial and keep (no) (Al-Andalusi, 2010).

The linguistic structures have adopted several methods for deleting the predicate. Like, in Answer to the interrogation with (who), (any), or (what), the semi-sentence has included the interrogative that is about (who is present), (who is with you), and (what you have). Similarly, if a noun sentence has turned to a noun sentence for the predicate, the word and meaning are united. It is permissible to omit the predicate from one of these, as the second indicates it. However, it is not permissible to omit the negative report about (what) the or one of its sisters, unless (what) is included in the negation subject (who) to (if). However, it is permissible to omit the approach's predicate and hope verbs chapters (almost and perhaps). It is mentioned: "Then make a wipe with the market and the necks.

Then estimator came to wipe it completely" (Al-Nahas, 2000). Grammarians have favored Sibawayh's opinion that it is permissible to delete the predicate in the chapter on the accusative letters of the name that raises the predicate (that) and its sisters. In the linguistic eloquence methods, Almighty God says: "Those who disbelieve and turn away from the path of God and the mosque, which made it for people both the mosque resident and annihilated" (Qur'an 22:25). Here, the predicate has deleted the estimator when saying: "and annihilated. Here, estimation is lost or perished" (Al-Andalusi, 2021). As for the predicate (no) that denies gender, it is included in the noun sentence. It is the work of (that) in the accusative of the subject and the predicate's raising. It is frequently omitted in the Hejazi statements: "If the person knows the significance of a previous pronouncement or a current context" (Al-Andalusi, 2010).

Regarding deleting the two parts together (the subject and the predicate), it is permissible in the Arabic language to delete the two parts together (the subject and the predicate) if evidence indicates these. The deletion usually occurs after an interrogation as (Where is Zaid sitting?), (when is Omar traveling?), and (which place do you live?). It is answered in such and other things: (At home), (tomorrow), and (in Cairo). Here, it is estimated: (Zaid is sitting at home), (Omar is traveling tomorrow), and (I live in Cairo), and there are many more. Here, the letter of the affirmative is located instead of it. Like, it is questioned: (Is Amr free?), it is answered: (Yes), and it is estimated: (Amr is free). It is not 
permissible to delete the nominative sentence abrogated by a verb or a letter other than which is abrogated by a verb in the heart verbs section (thinking and its sisters). So, it is permissible to delete the two verbs consisting of a noun sentence of a subject and a predicate, which may be deleted together in short.

\section{The Progress and Delay Between the Two Parts of The Chain of Transmission in Linguistic Compositions}

The origin of the linguistic construction is governed by a structural template of a specific order. Because the expressions are not considered useful until they constitute a particular form of composition, these are deliberately used without a form of composition and arrangement (Al-Jarjani, 2001). This statement is based on the order of words to denote the meanings inherent in the same speaker. Because if you have finished the arrangement of meanings in yourself, you do not need it until you resume thinking about the arrangement of words (Al-Jarjani, 2020). Therefore, postulated in the text language science, the correct reading of vocal production is related to the words' arrangement (Madkour, 1987). According to the language system and the Arabic linguistic structures, they have produced the rank. It has developed a relationship between two arranged parts of the context.

The meaning is indicated by the location of each of these on the others. Sibawayh (1988) is considered one of the early grammarians who have applauded linguistic structures' progressing phenomenon. It is said: "Good Arabs, as they have progressed only about what their statement have more important, they are richest" (Shebel, 2009). Progress and delay in the Arabic language have changed the basic structure (Matlob, 1987). Progress is entitled to delaying, and the delay is entitled to progressing. It has developed a kind of rhetoric in speech.

The linguists have agreed on a set of controls through their analysis of the Arabic linguistic discourse. They have considered it justified to depart from the original structure. It is achieved by progressing the consequences of delay or delaying the consequences of progress. Among the controls of linguistic structures, the first is regarding the composition. The Arabs are accustomed to composition in their speech. It is done on their tongues, and their scholars applaud it. Therefore, they have accepted in their words: (Zaid struck Abdullah). They have done it by progressing the object on the subject. Similarly, he replied: (Your brother Abdullah). Here, the first has flowed from their tongue, and the second has contravened their use. Therefore, the use of Arabs is a strong bond that is considered when using the language (Al-Waderni, 2004). In Arabic, a set of strucure is not permissible to precede some of its parts over others. Once the name relates to its link, it is not permissible to progress any part of its relationship with it in the manner (Who struck Zaid Amr) (Ibn Al-Serag).

Once the name is added with the additive, it is not permissible for the additive or any of its parts to precede the additive. Similarly, once you have arrived at the source letters, it is not permissible to precede these badly from what it arrived at, as in the manner (To master your work is better for you). Likewise, the Answer with the condition and the oath with its Answer is not permissible for the Answer to be preceded by these. Moreover, it is not permissible to submit the predicate associated with (additional with) over the subject. The Arabs have in their language tools called the primacy tools, such as (L) the beginning, (L) oath, or interrogative tools. The primacy distinguishes these tools in the composition, so it is not permissible for anything to precede these in the sentence in which it is located. While constructing the verb with its subject, as (The worker's attendance), it is not permissible for the subject to precede its agent in such a constructing where the occurrence and renewal are intended. The object method is not permissible to precede the obover its verb (liked the night). Besides, it is not permissible to precede the action of verbs that are not disposed of, such as (yes), (maybe), exclamation, (not), and the nouns of verbs.

Furthermore, it is not permissible to progress the letters working on it, such as the prepositions. It is not permissible to progress the noun on it and chapter's letters (that) and its sisters. It is not permissible to progress the noun from the predicate or the verb, as (But Zaid is standing), and (Zaid is not struck except Omar). Here, it is unknown who is trapped in it except with delay (Al-Shatibi, 2007). The second control among the controls of linguistic structures is regarded as deviating from their arrangement's origin. It is not intended to confuse the addressee. It maintains the clarity of the meaning without confusion. Suppose the evidence is found that distinguishes the subject from the news. In that case, it is permissible to present the subject to the predicate even if the grammarians agree on a definition or denial. Likewise, the subject must be preceded by the object if there is fear that one of these would be confused with the other. As in the manner of (Moussa struck Essa), this rule is governed by saying in the Ibn Malik (The effect is delayed if worn with caution) (Al-Andalusi, 1967).

It is denoted that the object must be delayed, and the subject should be preceded. Since no presumption distinguishes one of these from the other, it is permissible to pertain to the word due to the 
lack of syntax that distinguishes the meanings. It is not allowed to progress in a place where the fear of confusion and disruption of the meaning is overlapped between discrimination and the situation as in the manner (You honored uncle). Here, it stands up to discrimination and may not take precedence over what has been done in it (Al-Khatib, 2006). The third control is concerned with the progress, which is linked to the speaker's intention to care for the presenter. So, the progress is based on the amount of care and concern for the one who has presented it as Almighty God says: "As for the orphan, do not subjugate it, and as for the questioner, it does not cease to work" (Qur'an 93:9-10). The progress of the object (the orphan and the questioner) reveals the extent of the interest in taking care of these. One of the essential meanings that linguists have monitored for progress in linguistic discourse is the specification. It constitutes the essential purpose that calls for submission.

Regarding the predicate's progress on the subject, grammarians have agreed upon the general rules when constructing the nominal sentence. The basic principle is that the subject takes precedence over the predicate, which is delayed in the original story (Al-Shatibi, 2007). This rule is not disputed among the grammarians because the analogy in it has agreed to the usage. It is found that the novice is a factor in the predicate, and the rank of the worker is in front of the noun, and this is a common origin. Likewise, the bulk of the linguistic use in the speech of the Arabs has advanced the beginner over the predicate. Hence the linguistics used in the speech of the Arabs has agreed with the grammatical analogy. So, the grammatical base is built through these two origins (measurement and hearing). This principle has presented the subject and has delayed the predicate. It is permissible to depart from this principle by presenting the predicate and delaying the subject unless it prevents an objection (Zaid standing) and (your brother's serum). Here, the subject has deserved its characteristic by its behavior. It is meant that it is fit to be a subject, object, or additive. Once it is acting, and it deserves to dispose of its work with progress or delay.

The nominative sentence is progressed and delayed with the transcribers, like (was) and its sisters. The name of the (was) rule is assigned to its (subject) in the actual sentence. It is not permissible to progress it on the chapter's tools (was) and its sisters. This is because the subject is reduced to its action, and in some grammatical sources, it is called a subject (Al-Andalusi, 1967). As for the predicate, it is permissible to dispose of it by the progress the name by mediating between the copyist and its name, for example: (Zaid was standing), and (Amr's became free). Arabic words have justified the departing from the original in this place, which is the conduct of actions in them. The fundamentalist's rule has required that every worker who behaves disposes of his actions (Al-Shatibi, 2007).

The chapter of the Predicate verbs may be preceded except in two places. In the first place, the predicate (continuous) has been associated with (not). As it does not fulfill its intended meaning with the predicate unless it is associated with (not), so the predicate after it is related to it. The second place, for (not) it is not permissible for it to be reported before it. Because it is an act that is not acting, and it is not permissible for the course of actions to be conducted except in the narrowest limits. Like, (It is not) has served as (not) in meaning and action, and (not) is not valid in it to give its experience to it.

Regarding approach, hope, and initiation verbs, verbs of this section have indicated the approaching of the predicate to the informant. It anticipates its occurrence or initiates it. The principle was that it was included in the chain of "was" and its sisters. However, it was singled out for it. Its story was nothing but a verbal sentence associated with "that" in some of it and abstracted from it in others, according to each verb's significance and its function in the composition. This feature was specified to the predicate verbs of this section and was prevented because of it. So, it is not permissible for the predicate in this section to be preceded by the copyist verb. It has been committed in the report to be a verbal sentence. This is contrary to the origin. Many of the chapter verbs have become weak in the past form, that they are always present (Al-Andalusi, 2010).

Regarding the abrogating letters (if) and their sisters, these have consisted of the abrogating letters (that), (as), (but), (hope), and (perhaps). These are characterized as abrogating tools that enter the noun sentence (the subject and the predicate). It changes its meaning and rule. It has worked opposite of what for (was) from work. The initiator puts a name for it and raises the news to was (Zaid is diligent) and (I like that he is rich, but he is stingy). If these tools enter the nominal sentence, then their agents are obligated to arrange these. It is not permissible for their knowledge to come before them due to their lack of action. So, they do not dispose of their employees as they (was) and its sisters do in their clients. It is also not permissible for (also) for its predicate to mediate between it and its name except in two specific places that are used in the Arabic words. First is regarding the predicate, it is a semi-sentence (adverb, current, and tragic) as (Zaid is in front of you).

The second is regarding the noun, and it includes a pronoun that refers to the predicate semisentence. The predicate must be preceded, and the name must be delayed as (There are workers in the factory). There is a difference between the two previous cases of submission in terms of judgment. The 
first has progressed in it, and it is permissible and is left to the speaker. Whether it is preceded or another requires according to the meaning. In the second case, it has progressed in it as an essential duty by the grammatical profession. (No) it denies gender from subject and predicate (No). You have entered the nominal sentence that makes the subject a name for it and raises the predicate as a predicate for it. This work is carried on the chapter (that) and its sisters to the similarity between these. The provisions are stipulated in the method denied by (no), which is used in denying gender. It is not permissible for it to take precedence over it. It does not mediate between it and its name even if it is a semi-sentence as is justified. The predicate is prevented from being presented to it. This is due to its being a tool negation. It falls into the space of negation, which may not take precedence over the negation instrument. As for its entitlement to the top of the sentence, and as for the commitment to the rank in the subject and the predicate, this has failed to act (no) in the predicate, which is the basis for it in work.

Heart verbs of the two parts of the transmission chain are transcended to the two objects of their origin, the subject and the predicate. Some of which are related to indicating the assumption of certainty. That is why these are called heart verbs. Some of these are concerned with the conversion indication. The verbs have not been arranged between the copyist and its actions. So, it is not objected in the linguistic text for the copyist to lead these together, be late to these, or mediate between these. Here is an example of the copyist's progress (The ignorant thinks the lie is a savior). Similarly, an example of delaying is (Lying, the ignorant thinks he will escape) and (A savior thinks the ignorant is lying).

\section{CONCLUSIONS AND RECOMMENDATIONS}

It is determined that the declarative structure study has played an influential role in revealing sentence meanings and speech purposes. Deletion of linguistic structures is subjected to control. The presence of a trace indicates the omitted form, whether it is a syntactic movement, a meaning required by the composition, or a factor that requires an action. Besides, there will be evidence in the speech that indicates the omission. One of the Arabs customs in their speech is that nothing omits something obligatory or permissible except with evidence. Moreover, its appearance does not violate the meaning. The basic principle in linguistic structures is based on maintaining the meaning's validity and relevance to the context.

The progress and delay are the Arabic language characteristics that allow the speaker to skip the basic rules in arranging the syntax. The linguists have agreed on a set of controls that justifies departing from the original structure. It validates by progress which should be delayed, or by delaying which should be preceded. It emphasizes that the composition should be what the Arabs are accustomed to being in their words. Besides, it explains that the departing from their arrangement's origin is not to confuse the addressee. It maintains the clarity of meaning. Moreover, the progressing is related to the intention of the speaker to take care of the preceded. So, the progressing is based on the care and attention of the precedent.

After extrapolating the origin phenomenon in the linguistic code, our research recommends studying the phenomenon of deviating from the original in all linguistic methods in the linguistic code. Moreover, it emphasizes studying the phenomenon of deviating from the original in the linguistic, religious, and literary heritage to reveal the aesthetics of the style, semantic values, and deliberative dimension.

\section{ACKNOWLEDGMENTS}

This project is supported by the Scientific Research Deanship at Prince Sattam Bin Abdulaziz University through Research Project No. 16624/2/2020.

\section{REFERENCES}

Al-Akbari, A. A. (1992). Under Muhammad Khair Al-Halawani. Controversial issues in grammar, Dar AlSharq Al-Arabi, Beirut Edition: First, Beirut, pp. 35.

Al-Andalusi, . M. (1967). Facilitating benefits and complementing objectives, under Muhammad Kamil Barakat. House of Arab Book Printing and Publishing, Riyadh, pp. 52.

Al-Andalusi, A. A. (2021). Under Abd al-Salam Abd al-Shafi Muhammad. The brief editor on the interpretation of the book. Publisher: Dar al-Kutub al-Ilmiyya - Beirut Edition, Beirut, 4/115, $5 / 240$.

Al-Andalusi, A. H. (2010). Under Hassan Hindawi. Appendix and supplement to explaining the book of facilitation. first edition, Dar Treasures of Seville, Riyadh, 4/251, 4/350. 
Al-Jarjani, A. A. (2001). Rhetorical secrets, under Abd al-Hamid Hindawi. Publisher: Dar al-Kutub alIlmiyya, Beirut Edition: First, Beirut, pp. 2.

Al-Jarjani, A. A. (2020). Evidence of Miracles, under Yassin al-Ayoubi. , First edition , The Modern Library, The Model House, p. 69.

Al-Khatib, M. (2006). The Rules of Grammatical Thought, (2/130, 2/134, 229, 2/295, 2/353), The Theoretical and Application of Text Linguistics by Azza Shibl. Dar Insights, Cairo, p. 115-116.

Al-Nahas, Abu Jaafar (2000). The translation of the Qur'an: translated by Abd al-Munim Khalil Ibrahim, Muhammad Ali Baydoun publication. Dar al-Kutub al-'Ilmiyya, Beirut Edition: First, Beirut, 3/49, 3/311.

Al-Shatibi, I. A. I. (2007). The healing purposes in explaining the adequate summary under Ayyad AlThubaiti. First Edition, Center for the Revival of Islamic Heritage at Umm Al-Qura University, Saudi Arabia, 2/54, 2/73, 2/158.

Al-Tamimi, I. W. (1995). The victory of Sibawayh over the radiator, translated by: Zuhair Abdul-Mohsen. Foundation of the Resala, Beirut, pp. 203.

Al-Waderni, A. (2004). The issue of pronunciation, meaning and poetry theory among the Arabs. Dar AlGharb Al-Islami, Beirut, p. 190.

Al-Zamakhshari, A. (1993). Al-Muftil in Arabic, under Ali Bou Melhem. First Edition, Al-Hilal Library, Beirut, p. 23.

Brinker, K. (2010). Linguistic analysis of the text. Translation, Saeed Buhairi. Al-Mukhtar Foundation, 2nd Edition, Riyadh.

Hammouda, D. T. (2020). The phenomenon of deletion in the language lesson. University House, Alexandria, p. 202.

Hassan, A. (2020). Comprehensive Grammar. Dar Al Maaref, Cairo, Ninth Edition, Cairo.

Ibn Al-Serag. The origins (2 /223).

Madkour, D. A. (1987). Arabic linguistics and the modern lesson. House of Culture for Publishing and Distribution, Riyadh, p. 199.

Mahdi, M. (1990). Orientalism and the study of Islamic philosophy. Journal of Islamic Studies, 1, 77-98.

Matlob, A. (1987). Rhetorical Research. First Edition, Dar Al-Fikr for Publishing and Distribution, Riyadh, pp. 41.

Shebel, D. A. (2009). Text language science theory and practice. Literature Library, Cairo.

Sibawayh, A. (1988). The book, under Abd al-Salam Muhammad Harun. Third edition, Al-Khanji Library, Cairo.

Sunan al-Nasa'i. Chapter on the mention of the most tormented people (8/216). 